This item was submitted to Loughborough's Research Repository by the author.

Items in Figshare are protected by copyright, with all rights reserved, unless otherwise indicated.

\title{
Intelligent models for predicting levels of client satisfaction
}

PLEASE CITE THE PUBLISHED VERSION

http://dx.doi.org/10.1142/S1609945104000164

\section{PUBLISHER}

(C) World Scientific Publishing

\section{VERSION}

AM (Accepted Manuscript)

\section{PUBLISHER STATEMENT}

This work is made available according to the conditions of the Creative Commons Attribution-NonCommercialNoDerivatives 4.0 International (CC BY-NC-ND 4.0) licence. Full details of this licence are available at: https://creativecommons.org/licenses/by-nc-nd/4.0/

\section{LICENCE}

CC BY-NC-ND 4.0

\section{REPOSITORY RECORD}

Soetanto, Robby, and David G. Proverbs. 2019. "Intelligent Models for Predicting Levels of Client Satisfaction". figshare. https://hdl.handle.net/2134/16604. 


\title{
Intelligent models for predicting levels of client satisfaction
}

\author{
Robby Soetanto $^{1}$ and David G. Proverbs
}

\author{
School of Engineering and the Built Environment \\ University of Wolverhampton \\ Wulfruna Street \\ West Midlands WV1 1SB \\ United Kingdom
}

${ }^{1}$ Author for correspondence, Phone: +44 1902 322108, E-mail: R.Soetanto@wlv.ac.uk 


\begin{abstract}
Presents the development of artificial neural network models for predicting client satisfaction levels arising from the performance of contractors, based on data from a UK wide questionnaire survey of clients. Important independent variables identified by the models indicate that long-term relationships may encourage higher satisfaction levels. Moreover, the performance of contractors was found to only partly contribute to determining levels of client satisfaction. Attributes of the assessor (i.e. client) were also found to be of importance, confirming that subjectivity is to some extent prevalent in performance assessment. The models demonstrate accurate and consistent predictive performance for 'unseen' independent data. It is recommended that the models be used as a platform to develop an expert system aimed at advising project coalition (PC) participants on how to improve performance and enhance satisfaction levels. The use of this tool will ultimately help to create a performanceenhancing environment, leading to harmonious working relationships between PC participants.
\end{abstract}

Keywords: artificial neural network, client satisfaction, contractor performance, performance assessment, project coalition

\title{
1. Introduction
}

Traditionally, the main participants of the construction project coalition (PC) are the client, the architect, and the contractor. The interactions and interrelationships between these participants largely determine the overall performance of a construction project (Smith and Wilkins, 1996; Egan, 1998). The performance of these participants is also interdependent (Higgin and Jessop, 1965; Mohsini, 1989). Hence, in order to perform effectively, a reciprocal requirement exists, whereby each participant requires the other participants to perform their duties effectively and in harmony with others. Notwithstanding this mutual 
dependency, the performance of individual participants remains important because overall project performance is a function of the performance of each participant (Liu and Walker, 1998).

U.K. contractors have long been criticised for their failure to fulfil the needs of their clients (Latham, 1994; Egan, 1998). In a broader sense, contractors should also perform to the satisfaction of other PC participants (e.g. architects) to maintain harmonious working relationships. This is because harmonious working relationships are essential if projects are to be successful (Baker et al., 1988; Smith and Wilkins, 1996; Egan, 1998). There is a need therefore, to investigate contractor performance from the viewpoint of other PC participants (especially clients), from which a tool for predicting levels of (client) satisfaction could be developed. This will help to improve performance and enhance satisfaction for the betterment of overall project performance. Development of this tool (in the form of artificial neural network models) are presented and described.

\section{Determinants of satisfaction in the performance assessment}

Figure 1 illustrates the relationship between performance and satisfaction in the context of performance assessment. Performance outcomes are the input and levels of satisfaction / dissatisfaction are the output. Between the input and output, a psychological processing or 'black box' exists. That is, an observer can see only what goes in and what comes out, not what occurs inside (Oliver, 1997). Additionally, this psychological process is subjective and difficult to interpret. Satisfaction is regarded as an internal frame of mind, tied only to mental interpretations of performance levels (Oliver, 1997). This indicates that a performance assessor (e.g. client or architect) will have their own psychological interpretation of the performance of others (e.g. contractors). 
Figure 1 about here

Smith et al. (1969) argued that satisfaction can be specifically defined as a function of the perceived characteristics of a performer in relation to an assessor's frame of reference. They further stated that for given situations, expectations and experience play important roles in providing the relevant frame of reference. Here, frame of reference is defined as the implicit standard (or standards) a person uses in making an evaluation. Individuals may have different standards in their judgement of performance, for example, different persons enter the same objective situation with different frames of reference, which affect both their summary evaluation of the situation and the aspects of that situation which are pertinent to their judgements. This concurs with Jayanti and Jackson (1991) who opined that a consumer's individual differences should be taken into account when attempting to explain satisfaction with services. A better understanding of the judgements made by individuals can be obtained by better understanding their frame of reference.

However, gaining knowledge of an individual's frame of reference is considered a very onerous, if not impossible, task. Investigating underlying attributes forming an individual's frame of reference is relatively easier. From this, it is argued that attributes of the assessor, i.e. those which impact their feeling of satisfaction, may influence their judgement of performance.

\section{Conceptual model of performance assessment}

Conceptually, the outcomes of performance assessment (in terms of levels of satisfaction) can be influenced by two major attributes, those of the performer (i.e. performance attributes) and 
those of the assessor (i.e. satisfaction attributes). Satisfaction attributes are differentiable from performance attributes mainly due to their unique nature; they being inherent within an individual (i.e. assessor). That is, performance attributes may reflect on both participants and projects, and will influence both participant and project performance. In contrast, satisfaction attributes reflect solely on the assessor and influence their performance assessment and as such are beyond the control of the performer. A list of all performance and satisfaction attributes identified from the literature is presented in Table 1 (column 1).

\section{Table 1 about here}

Performance attributes consist of participant attributes and project attributes. Participant attributes represent the characteristics or nature of a particular participant or their organisation, such as company age, turnover, etc. Project attributes represent the characteristics / nature of a project, comprising attributes which are either controllable or not. Controllable attributes are for example, forms of contract, procurement route, extent of design completed prior to work on site, etc. Uncontrollable attributes are for example, type of project, ground and weather conditions, etc.

Satisfaction attributes include the personal attributes of the individual assessor (e.g. experience, vocational background, etc.) and attributes of their employer (e.g. company assessor attributes). Company attributes are characteristics of the assessor's company, which may influence their assessment (e.g. company age, turnover, number of employees, etc.).

Figure 2 demonstrates the relationships between these variables. The performance attributes of a participant have a direct influence on their own performance in the construction process. 
Project attributes indirectly influence the participant's performance since the attributes may enable / hamper the participant in executing their duties. Performance assessment in this respect is considered as 'objective' (i.e. tangible) in nature. For example, contractor performance may be assessed in terms of cost, time and quality performance (Holt, 1995).

\section{Figure 2 about here}

However, performance assessment goes beyond the objective aspects outlined above since it considers the feelings of the assessor, which in turn is dependent on their background, i.e. frame of reference. This assessment is considered 'subjective' and at a higher level. This research embraces both 'objective' and 'subjective' (or higher level) performance assessment. In this case, satisfaction is measured using predetermined performance criteria, which are explained in the following section.

\section{Research methodology}

In the context of this paper, contractor performance criteria are defined as those used to measure the performance of contractors based on the views of clients. These criteria were determined through interviews with twelve experienced clients and supported by literature review in the domain of (contractor) performance. For further detailed description of these interviews and the methods of analysis adopted, refer to Soetanto et al. (2002). A comprehensive list of these criteria can be seen in Table 2 (column 1). 


\section{Table 2 about here}

To provide the main modelling data, a questionnaire was developed based on the attributes and performance criteria identified. Respondents (i.e. clients) were asked to identify a recent (i.e. within 2 years) UK building project in which they were involved (referred to as the 'case project'). Respondents were asked to relate all their answers to the questions contained in the questionnaire to this one 'case project'. This strategy was designed in order to capture a true and realistic reflection of assessors' satisfaction / dissatisfaction feelings. To protect the confidentiality of the other parties involved in these case projects, respondents were not asked to identify projects, nor name other participants.

Following the development of the questionnaire and implementation of a pilot survey, a UKwide questionnaire survey of clients was conducted. Due to the comprehensive nature of the questionnaire, a two-stage distribution strategy was used with the intention of generating more responses. Data collected from the first stage of this strategy were subjected to preliminary analysis using bi-variate correlation analysis between attributes (as independent variables) and performance criteria (as dependent variables) to identify likely significant attributes influencing expressed satisfaction / dissatisfaction. The purposes of this analysis were two fold: first, to obtain a more manageable (i.e. smaller) number of variables which had the potential to be important variables and so allow efficient and effective analysis to be conducted; and second, to reduce the length of the questionnaires to be used in the second stage survey in order to obtain the response required to allow meaningful statistical analysis. Possible significant attributes for modelling is presented in Table 1 column 2. 
First stage distribution involved 266 experienced U.K. private and public clients, defined as those who regularly procure construction works from the industry. Private clients consisted of developers, retailers and financial institutions. Retailers and financial institutions were identified from the listing of Key British Enterprises (Dun and Bradstreet, 1998) representing the top U.K. retailers and financial institutions. Developers were identified from the Estates Gazette (1999). Public clients, i.e. local authorities or City Councils, were identified from the Municipal Year Book (Lauren Hill, 1999). Thirty-nine responses were received representing a 14.7 percent response rate. Targeting similar types of clients, second stage distribution involved 270 clients. Thirty-eight responses were received representing a 14.1 percent response rate. This suggests that the two-stage strategy did not improve the response rate. Perhaps, the response towards a questionnaire survey may depend solely on the interest of the respondents.

Overall, seventy-seven responses were received representing a $14.4 \%$ response rate. This relatively low response rate is about the 'norm' for construction management research and in many ways can be associated with the 'confidential' nature of the questions and the comprehensive nature of the research instrument. About two-thirds of the responses (50 responses) were used to develop the models and the remaining (27 responses) were used to validate the models. It is acknowledged that the sample size was rather small particularly in respect to the method used (i.e. artificial neural network / ANN) and therefore caution had to be taken into account in interpreting the models, particularly with regard to their accuracy and consistency. However, ANN is a powerful technique and can still capture the relationships between independent and dependent variables, even with such a limited sample. For example, using a similar software package, application and sample size, Cheung et al. 
(2000) successfully developed a model to predict the likelihood of project dispute resolution satisfaction in Hong Kong.

\section{Performance measures (i.e. dependent variables)}

In this research, satisfaction is measured using an interval scale (i.e. scale 0-10) which assumes that satisfaction is a matter of degree, not an all or none property. To measure an abstract concept such as satisfaction, the concept should be defined at an operational (i.e. lower) level, which is observable and directly measurable. If the relationship between the abstract concept and the operational definition of satisfaction (i.e. performance criteria) is strong, the measurement instrument can be considered as valid and reliable to represent the abstract concept. For a full description of the validity and reliability of empirical measurement, readers may wish to consult Bohrnstedt (1970), Carmines and Zeller (1979) and Nunnally (1978).

To derive satisfaction measures, the factor analysis technique was applied to the performance criteria of 50 responses (i.e. case projects) which were used to develop the models (27 were held-back for validation purposes - see later). The main purpose was to determine the number of common factors (i.e. satisfaction dimensions) that would satisfactorily produce the correlations among the observed variables (Kim and Mueller, 1978). The factor structure matrix (as shown in Table 2, column 3-7) was examined to identify the performance criteria for each factor / dimension. Each dimension consists of several performance criteria, which have highest factor loadings on that dimension. Performance criteria that had their second highest factor loadings within 0.10 of their highest ones were not used to define any dimension (i.e. deleted) (Torbica, 1997). This is because these criteria do not uniquely 
contribute to any dimension (Kim and Mueller, 1978). Five dimensions of client satisfaction were obtained from this process.

The scores of the performance criteria under each dimension were then averaged to obtain the satisfaction measure (i.e. factor score). The factor score serves as an index of attitude towards a particular dimension of concept (i.e. satisfaction) under investigation (Torbica, 1997). From the original 48 performance criteria, 28 were included in one of the five factors (refer to Table 2).

The first factor (satisfaction measure-1 or satis1) included quality of hand-over document (O\&M manual, H\&S) (C3), telephone inquiries and correspondence handled courteously and adequately (Q2), speed and reliability of service (Q3), ability to make rapid decisions (Q5), administration (Q8), keep the client informed (A4), communication (to coalition member and site person) (A5), and responsibility for their decision (understand the cost of his recommendation) (A8). These criteria were meaningfully and logically interpreted as 'quality of service and attitude of contractor.'

The second factor (satis2) covered completion of defects (C1), ease / speed of settlement of final account (C4), ease of delivery (general feeling on how things went) (C5), adherence to schedule (M1), adherence to budget (M2), and quality of construction and workmanship (M3) which were interpreted as 'main performance criteria and completion.'

The third factor (satis3) included first interview and presentation (P1), ability and willingness to help develop brief (P2), contribution to design and buildability of project (P3), plan of 
work and method statement (P4), and understanding of contract and specifications (P5) which were interpreted as 'performance in preliminary stage.'

The fourth factor (satis4) comprised cooperation with client (E1), individual performance and ability (E2), project manager performance and adequacy of authority (E3), collaborative / spirit of cooperation / team-work (A2), and proactive attitude toward problems (A6) which were interpreted as 'performance of site personnel.'

The fifth factor (satis5) included material management (R1), equipment and plant management (R3), concern / awareness of environmental issues (R7) and site manner (i.e. no loud noises and swearing) (E4) which were interpreted as 'performance in resource management.' Additionally, two further measures were derived from the mean of satis1 to satis5 (avesat), and the overall satisfaction of contractor performance derived from one question in the questionnaire (totsat). Totsat is unique because it represents an individual (i.e. generic) satisfaction score as expressed by clients.

The validity and reliability of satisfaction measures were assessed. The results were found to be valid and highly reliable. For a full description of the methodology employed, readers may wish to consult Soetanto and Proverbs (2002).

\section{Modelling using artificial neural networks (ANN)}

The Artificial Neural Network (ANN) technique can learn from data presented and capture underlying relationships between input (i.e. independent) and output (i.e. dependent) variables even if they are difficult to find and describe. ANN can cope with noise, imprecision and complexity, which are not uncommon in the real world (Hammerstrom, 
1993). Due to this, ANN can learn complex non-linear relationships between dependent and independent variables. This also enables ANN to approximate interactions among the independent variables.

In construction management, there are vast examples of ANN applications from the last decade (1990s). This is because ANNs are particularly suitable for analogy-based decision problems prevalent in construction (Moselhi et al., 1991). Given the 'soft' nature of satisfaction and the involvement of subjective judgements, the data may be noisy, biased, complex and non-linear. Moreover, there are a large number of attributes (i.e. input variables) which must be considered in parallel (Moselhi et al., ibid.). These, therefore, justify the use of ANN as a tool for predicting satisfaction levels.

\subsection{Development of ANN Models}

In general, the development of ANN models comprises three phases, i.e. design, learning and recall (Moselhi et al., ibid.) (refer to Figure 3). The design phase involves analysing the problem (i.e. to identify attributes and performance criteria), consideration of design (for example, classification or regression problem), selecting the neural paradigm, and determining neural and learning variables. Determining the architecture of an ANN model is based mainly on trial and error subject to several rules of thumb suggested in the manual (NeuroDimension, 1999) and literature (Boussabaine, 1996; Hua, 1996; Akinsola, 1997; Edwards, 1999). The learning phase mainly involves 'training' or presenting the data into the designed network (i.e. run the programme). The design and learning phases are a repetitive process involving changing the network and learning variables to find an optimum model. The recall phase involves testing the trained network or putting the network into use. Similarly, in this phase, if training seems to arrive at an optimum model, but the network fails 
to provide good generalisation (i.e. possibly due to overtraining), the network and learning variables have to be altered and the network retrained (as shown in the loop in Figure 3). NeuroSolutions neural network simulation environment version 3.02 consultants level was used (NeuroDimension, 1999) to develop the ANN models.

\section{Figure 3 about here}

Multilayer Perceptron (MLP), an ANN paradigm commonly used for general classification and regression problems, was used here (refer to Figure 4). This paradigm normally contains three layers of processing elements, i.e. input, hidden and output layers. The input layer contains input data, hence the number of processing elements in this layer is equal to the number of variables. The hidden layer(s) are where the mathematical calculations of weights are conducted. The output layer represents the computational output of the network, here satisfaction levels.

\section{Figure 4 about here}

To find an optimum model, a two-stage development process was adopted. Firstly, to identify sensitive (i.e. important) independent variables, sensitivity analysis was applied (NeuroDimension, 1999). Here, sensitivity analysis was used to prune redundant or superfluous variables which may hamper the development of the 'best' model. The NeuroSolution package provides a useful facility for this purpose, that is 'sensitivity about the mean.' This sensitivity analysis was run by varying the input between the mean \pm one standard deviation while keeping all other inputs constant at their respective means. Then the network output was computed for 50 steps above and below the mean. This process was 
repeated for each input variable. The software package produced a report listing the sensitivity factor for all input variables.

After the first stage, insensitive variables were pruned, leaving sensitive variables for inclusion in the second stage. The second stage of model development followed a similar process to that shown in Figure 3. This yielded a simpler model to those developed from the previous stage. This final model could then be used to predict client satisfaction levels. For the purpose of brevity, only the second stage models (i.e. final models) are presented and discussed.

\section{Client satisfaction models}

In total, seven models were developed to predict levels of client satisfaction based on contractor performance. Table 3 shows the network typology for the client satisfaction models. Table 4 shows the independent variables used to predict client satisfaction levels for each satisfaction measure (also each model). For each satisfaction measure, a sensitivity factor for each variable was produced. To obtain an overall picture of the variables used in the models, these variables were accumulated and their sensitivity factors summed. Based on this, Table 5 was produced which shows all variables included (first column) and their total sensitivity factors (TSFs) (second column). These variables could then be ranked according to their TSFs in descending order (third column). Based on TSFs, the variables could be categorised into four categories, i.e. extremely important (TSF $\geq 2.0)$, highly important (1.0 $\leq$ TSF $<2.0$ ), medium importance $(0.1 \leq \mathrm{TSF}<1.0)$ and some importance (TSF < 0.1$)$ (fourth column). 
Tables 3, 4, 5 about here

\section{Discussion of the models}

Of the 58 independent variables, 26 variables were identified as useful predictors in the client satisfaction models. These variables were categorised according to their importance (i.e. TSFs). Four variables were classified as extremely important, namely (i) any previous working relationship with the contractor's site personnel (COPERCL), (ii) method of contractor selection (COSELCO), (iii) type of building (PRTBD), and (iv) type of project (PRTPR). Here, a well-established working relationship at site personnel level would produce higher satisfaction levels. Further, the procurement of the contractor must be carefully considered. Due to its adversarial nature, the competitive tendering approach is likely to discourage good performance and hence lower satisfaction levels. In this case, a contractor selection methodology based on negotiation may encourage higher satisfaction levels. These two variables suggest that long-term relationships may encourage higher satisfaction levels. It is interesting to note that different types of building and project influence satisfaction levels. In the context of this research, they are considered uncontrollable attributes which can not be altered.

'Highly important' variables comprised (i) project procurement route (PRROU), (ii) overrun (PRDUROV), (iii) method of contractor payment (COPAYCO), and (iv) overbudget (PRBUDOV). Long-term, relationship based procurement routes, such as partnering and strategic alliances may have advantages over traditional competitive tendering routes. Moreover, contractors should also maintain their attempt to deliver projects on time and on budget whilst noting that these issues are not considered most important by clients. The lump sum method of payment may discourage satisfaction in contrast to, for example, cost 
reimbursement. Here, method of contractor payment should be carefully considered and negotiated before project commencement.

Variables categorised as 'medium importance' were dominated by contractor performance attributes. These included (i) experience with project size (COATTSI), (ii) current workload (COWL), (iii) quality control policy (COATTQC), (iv) general past performance of contractor (COATTPP), (v) past performance in quality of construction (COATTQU), (vi) past performance in project budget (COATTBU), (vii) health and safety policy (COATTHS), and (viii) formal training regime (COATTTR). Moreover, contractors should attempt to reduce variations since these have an adverse effect on satisfaction (PRVARCO). Interestingly, one respondent attribute representing the client's general perception of contractors regarding claim consciousness (RSCON2) was included here. That is, clients who perceive contractors to be claim conscious, are less likely to be satisfied.

Variables with 'some importance' included a mixture of project attributes, contractor attributes and respondent attributes. Project attributes were (i) the extent to which the project is constrained by weather conditions (PRCONWE), (ii) design complexity (PRCOMDE), and (iii) contractor and architect interaction prior to on site work (PRINT). Inclement weather may influence contractor performance and hence client satisfaction levels. Complex designs demand higher levels of contractor performance which will ultimately impact client satisfaction. Early interaction between architects and contractors fosters effective levels of buildability, thereby improving performance levels. Additionally, early interaction enables communication and the development of working relationships. 
Contractor performance attributes with 'some importance' included (i) the qualification and experience of site personnel (COATTSP), (ii) past performance in terms of adherence to schedule (COATTSC), and (iii) financial soundness (COATTFI). Respondent (i.e. client) attributes included (i) general perception regarding contractual attitude of contractor (RSCON4) and (ii) the overall satisfaction level arising from contractor performance in general (RSSATCO). That is, those clients who perceive contractors to adopt a contractual attitude, are likely to suffer lower satisfaction levels. Conversely, clients with a high perception of contractor performance in general, are more likely to yield higher satisfaction levels.

Based on this categorisation, contractors seem to have more control primarily over variables classified as 'medium importance,' and limited control over 'some' and 'highly important' variables. Variables classified as 'extremely important' were found to be largely beyond the control of contractors (e.g. procurement route, method of payment, etc.). Overall, it can be concluded that client satisfaction levels can only be partly controlled by contractors. However, the importance of contractor performance attributes should not be overlooked, instead contractors should focus on those attributes found to be significant in order to continuously improve performance and enhance client satisfaction.

The independent variables identified consist of project attributes, contractor performance attributes and respondent (i.e. assessor) attributes. Hence, this suggests the validity of the performance assessment model presented in Figure 2, i.e. that satisfaction levels are dependent on performance and satisfaction attributes. Hence, subjectivity is to some extent prevalent in performance assessment. 


\section{Model validation}

To confirm the robustness (in term of accuracy and consistency) of the models in predicting satisfaction levels, the models were validated using a hold-back sample of 27 case projects that had not been used to develop the model.

The predictive performance of the models was assessed by examining the residual (i.e. the difference between the actual and the models' predicted satisfaction levels). These were measured using two prediction performance measures, i.e. mean absolute deviation (MAD) and mean absolute percentage error (MAPE) (Kvanli et al., 1996). While MAD indicates the mean of absolute deviation of the predicted levels from the actual levels, MAPE indicates the mean of absolute percentage of that deviation from the actual levels. Using these measures, it could be concluded that a model yields predicted values with an average deviation of \pm MAD, which is MAPE \% from actual levels. For data of this nature, MAD of 1.5 to 2.0 and MAPE of 30 to 35\% are considered acceptable. MAD of less than 1 and MAPE of less than $20 \%$ indicate good predictive performance. The performance of the models was also tested using chi-square $\left(\chi^{2}\right)$ analysis and Pearson’s correlation coefficient (Edwards, 1999).

Results are summarised in Table 6. On average, the deviation of the predicted satisfaction levels is between 0.8 and 1.3 from 10 points scale (MAD), which is between 16 to 28 percent of actual levels (MAPE). This is quite good given the subjective nature of satisfaction / dissatisfaction judgements. Pearson's correlation tests confirmed that this level of accuracy is significant. Moreover, Chi-square tests confirmed that the models have consistent predictive performance. These indicate that the ANN models developed are valid and robust.

Table 6 about here 


\section{Application and beneficial outcomes of the ANN satisfaction models}

The validity and reliability of the ANN models developed have been demonstrated. In their present form, the models could be used to predict satisfaction levels. However, this could be enhanced by linking the statistical models to an interactive / more user-friendly software, possibly in the form of an expert system. This expert system would ask users to enter the relevant performance and satisfaction attributes necessary to develop the models. Then, it would 'transform' these attributes into input variables for the models. The outputs, i.e. satisfaction levels, could be computed and shown to the users. A further advance to this expert system would be to develop possible recommendations aimed at enhancing client satisfaction levels.

The expert system could be used by performer(s) (i.e. contractors) and / or assessor(s) (i.e. clients). For the performer, the results could be useful as an introspection tool aimed at improving performance as well as enhancing client satisfaction levels. For the assessor, the results could be used to select the 'best' contractor for a particular project. The results would also suggest what project environment (i.e. project attributes) is suitable to execute a particular project. The expert system itself would also serve as a project simulation tool, which could be used at any stage within the project life-cycle so that corrective actions could be taken to remedy problems. Benefits would be maximised if this tool could be used in initial project meetings among PC participants where problems could be identified early on, allowing them to be addressed (and hopefully resolved) before conflicts develop. For these to be effective, all participants must be prepared to be open, honest and exhibit a willingness to be criticised, constructively. This tool would be specifically beneficial for partnering or strategic alliances because it will also stimulate communication and cooperation among participants involved. 
In sum, the models developed could be used to predict client satisfaction levels which will improve contractor performance and enhance client satisfaction. This ultimately will help to create a performance-enhancing environment leading to harmonious working relationships between PC participants. This also ensures continuous performance improvement for the betterment of all involved.

\section{Conclusions}

Based on a UK wide questionnaire survey of clients, Artificial Neural Network (ANN) models have been developed to predict several dimensions of client satisfaction resulting from the performance of contractors. The problem solving approach and characteristics of ANN were found to be suitable for this because satisfaction has been recognised as a subjective judgement likely to be complex, non-linear and noisy.

The most important (i.e. extremely and highly important) independent variables identified suggest that long-term relationships may encourage higher client satisfaction levels. Additionally, uncontrollable project attributes, i.e. types of building and project, also significantly influence satisfaction levels. Moreover, contractors should maintain their attempt to deliver projects on time and on budget. Methods of payment to contractors should be carefully considered and negotiated before project commencement. Contractor performance attributes were classified as either medium or some importance, confirming that client satisfaction levels are only partly dependent on the performance of contractors. However, contractors should focus on those attributes identified in order to continuously improve performance and enhance client satisfaction. Overall, the models suggest that satisfaction levels are dependent on performance and satisfaction attributes. That is, the attributes of the individual assessor (i.e. client) were found to be of significance indicating 
that subjectivity is to some extent prevalent in performance assessment. The models showed accurate and consistent predictive performance over 'unseen’ independent data.

These models could be used as a platform to develop an expert system aimed at advising PC participants on how to improve performance and enhance satisfaction levels. Although this tool could be used independently by PC participants, maximum benefit could be gained if it were used jointly by all participants in project meetings, preferably in the early stages of project development. A stimulate to communication and cooperation among participants, the tool would be particularly useful for partnering and strategic alliances. This undertaking will ultimately help to create a performance-enhancing environment leading to harmonious working relationships between PC participants. This also ensures continuous performance improvement for the betterment of all involved.

\section{Acknowledgement}

The authors wish to acknowledge the practical feedback received from an audience of practitioners following presentation of the research at the CIOB Wolverhampton Centre Seminar held on $14^{\text {th }}$ February 2001 at Masonic Club, 211 Tettenhall Road, Wolverhampton, which led to a number of improvements being made to the paper.

\section{References}

Akinsola, A.O. (1997) An intelligent model of variations' contingency on construction projects. Unpublished Ph.D. thesis, University of Wolverhampton.

Baker, B.N, Murphy, D.C. and Fisher, D. (1988) Factors affecting project success. In Project Management Handbook, $2^{\text {nd }}$ edition, Cleland, D.I. and King, W.R. (eds.). Van Nostrand Reinhold, New York. 
Bohrnstedt, G.W. (1970) Reliability and validity assessment in attitude measurement. In Attitude measurement, Summers, G.F. (ed.), Rand McNally \& Company, Chicago, 8099.

Boussabaine, A.H. (1996) The use of artificial neural networks in construction management: a review. Construction Management and Economics, 14, 427-436.

Carmines, E.G. and Zeller, R.A. (1979) Reliability and validity assessment. Quantitative applications in the social sciences series No. 17, Sage Publications, Ltd., London.

Cheung, S.O., Tam, C.M. and Harris, F.C. (2000) Project dispute resolution satisfaction classification through neural network. Journal of Management in Engineering, ASCE, 16(1), 70-79.

Dun and Bradstreet (1998) Key British enterprises. Dun and Bradstreet, London.

Edwards, D.J. (1999) A methodology for predicting the total average hourly maintenance cost of tracked hydraulic excavators operating in the UK opencast mining industry. Unpublished Ph.D. thesis, University Of Wolverhampton.

Egan, J. (1998) Rethinking construction. The report of the Construction Task Force on the scope for improving quality and efficiency in UK construction. Department of the Environment, Transport and the Regions, London.

Estates Gazette (1999) Directory of property development and investment companies. August, 66-69.

Hammerstrom, D. (1993) Neural networks at work. IEEE Spectrum, June, 26-32.

Higgin, G. and Jessop, N. (1965) Communications in the building industry: the report of a pilot study. Tavistock Publications Limited, London.

Holt, G.D. (1995). A methodology for predicting the performance of construction contractors. Unpublished Ph.D. thesis, University of Wolverhampton. 
Hua, G.B. (1996) Residential construction demand forecasting using economic indicators: a comparative study of artificial neural networks and multiple regression. Construction Management and Economics, 14, 25-34.

Jayanti, R. and Jackson, A. (1991) Service satisfaction: an exploratory investigation of three models. Advances in Consumer Research, 18, 603-610.

Kim, J.O. and Mueller, C.W. (1978) Factor analysis: Statistical methods and practical issues. Quantitative applications in the social sciences series No. 14, Sage Publications, Ltd., London.

Kvanli, A.H., Guynes, C.S. and Pavur, R.J. (1996) Introduction to Business Statistics: A Computer Integrated Approach, $4^{\text {th }}$ ed. West Publishing Company, St. Paul / Minneapolis.

Latham, M. (1994) Constructing the team, Final report of the government/industry review of procurement and contractual arrangements in the United Kingdom construction industry. HMSO, Department of Environment, London.

Lauren Hill (ed.) (1999) Municipal year book 1999 and public service directory, Vol. 1: Functions and Officers. Newman Books, London.

Liu, A.M.M. \& Walker, A. (1998) Evaluation of project outcomes. Construction Management and Economics, 16, 209-219.

Mohsini, R.A. (1989) Performance and building: problems of evaluation. Journal of Performance of Constructed Facilities, 3(4), 235-242.

Moselhi, O., Hegazy, T. and Fazio, P. (1991) Neural networks as tools in construction. Journal of Construction Engineering and Management, ASCE, 117(4), 606-625.

Nam, C.H. and Tatum, C.B. (1992) Noncontractual methods of integration on construction projects. Journal of Construction Engineering and Management, ASCE, 118(2), 385398. 
NeuroDimension (1999) NeuroSolutions version 3: Getting started manual. NeuroDimension, Inc., Gainesville, Florida.

Nunnally, J.C. (1978) Psychometric theory, $2^{\text {nd }}$ ed. The McGraw-Hill Companies, Inc., New York.

Oliver, R.L. (1997) Satisfaction: a behavioral perspective on the consumer. The McGrawHill Companies, Inc., New York.

Puddicombe, M.S. (1997) Designers and contractors: impediments to integration. Journal of Construction Engineering and Management, ASCE, 123(3), 245-252.

Smith, A. and Wilkins, B. (1996) Team relationships and related critical factors in the successful procurement of health care facilities. Journal of Construction Procurement, 2(1), 30-40.

Smith, P.C., Kendall, L.M. and Hulin, C.L. (1969) The measurement of satisfaction in work and retirement: a strategy for the study of attitudes. Rand McNally \& Company, California.

Soetanto, R. and Proverbs, D.G. (2002) Modelling the satisfaction of contractors: The impact of client performance. Engineering, Construction and Architectural Management, under review.

Soetanto, R., Proverbs, D.G. and Cooper, P.A. (2002) A Tool for Assessing Contractor Performance. Journal of Construction Procurement, in press.

Torbica, Z.M. (1997) Total quality management and customer satisfaction in home building. Unpublished Ph.D. dissertation, University of Florida. 